\title{
Assessment of training need and training efficacy for national program for prevention and control of cancer, diabetes, cardiovascular diseases and stroke among medical officers of West Bengal, India
}

\author{
Indrajit Saha $^{1}$, Satabdi Mitra ${ }^{2} *$, Ananta Chatterjee ${ }^{2}$, \\ Jyotishman Mukhopadhyay ${ }^{2}$, Chitra Chatterjee ${ }^{2}$
}

Department of Community Medicine, ${ }^{1}$ Bankura Sammilani Medical College and Hospital, ${ }^{2}$ Jagannath Gupta Institute of Medical Sciences and Hospital, Budge Budge, Kolkata, West Bengal, India

Received: 23 April 2019

Accepted: 05 June 2019

*Correspondence:

Dr. Satabdi Mitra,

E-mail: stbdimtr111@gmail.com

Copyright: (c) the author(s), publisher and licensee Medip Academy. This is an open-access article distributed under the terms of the Creative Commons Attribution Non-Commercial License, which permits unrestricted non-commercial use, distribution, and reproduction in any medium, provided the original work is properly cited.

\section{ABSTRACT}

Background: The national program for prevention and control of cancer, diabetes, cardiovascular diseases and stroke (NPCDCS) has been rolled out in West Bengal, with its implementation initiated through state-wide training of Medical Officers (M.O). For attaining requisite competency for meeting NPCDCS objectives, MOs have been trained at their respective district levels. Present study aimed to assess the training need, training efficacy and need for further training.

Methods: A repeat cross-sectional study was conducted from May-July 2018 for M.Os of six randomly chosen districts of West Bengal, out of those whereat NPCDCS was launched in first phase. 40-45 M.Os were randomly selected from each district in liaison with district level health authorities. The total sample size was 352 with Finite population correction. On the days of training, pre and post training surveys were conducted with an identical semistructured, pre-tested and validated questionnaire (Cronbach's alpha $>0.8$ ) covering different levels of cognitive domain, with a maximum possible score of 100 marks. No negative marking was done for incorrect responses. Training was imparted by the Principal Investigator (accredited trainer). Ethical clearance was granted by the State Health Directorate. Informed consent from each participant was obtained.

Results: Dependent sample t-test revealed significant increment $(\mathrm{p}<0.0001)$ in post-test scores $(\mathrm{t}=63.134) \&$ one-way repeated measure general linear model (GLM) also revealed F=29.617 ( $<<.0001)$. The "Effect Size" was classified as "Huge" (Cohen's $\mathrm{D}=63.134 / \sqrt{ }(352)=3.365)$, as was noted between pre-test and post-test scores, based on Cohen's convention and Sawilowsky's addition. It was further noted that even after six hour training sessions there was $27.44 \%$ knowledge gap ( $\mathrm{p}<0.0001)$ after adjusting for Bonferroni.

Conclusions: Imperativeness of training coupled with periodic refresher training has been established as a prerequisite for successful implementation of NPCDCS.

Keywords: NPCDCS, Pre-test, Post-test, Medical officers, Training

\section{INTRODUCTION}

India is passing through rapid demographic, environmental and lifestyle related transitions. This has resulted into an "Onion peel phenomenon" symbolized by significant changes in magnitude and pattern of diseases across the country showing anupsurge in chronic non-communicable diseases (NCDs) including heart diseases, chronic lung diseases, cancer and diabetes, while communicable diseases and reproductive and nutritional disorders are on the decline. ${ }^{1}$ They are the leading cause ofdeath, accounting for over $70 \%$ of 
premature mortality and significant loss of DALY, placing them ahead of Communicable diseases, Maternal, Prenatal, and Nutritional conditions (WHO 2017). ${ }^{2}$ The Ministry of Health \& Family Welfare launched National Programme for Prevention and Control of Cancer, Diabetes, CVD and Stroke (NPCDCS) in October 2010. During the $11^{\text {th }}$ five year plan period, 100 districts over 21 states were covered and have been contemplated to extend to the entire country in $12^{\text {th }}$ five year plan., Under this programme, there is acceleration in setting up NCD clinics in CHCs and District Hospitals as well as number of people screened and identified with high blood pressure and/or high blood sugar. ${ }^{2}$ However, majority of the population did not have the opportunity for screening for high blood pressure and high blood sugar. Screening for common cancers (oral, breast and cervical cancers) also did not pick up to expected levels. NPCDCS has been launched with objectives of health promotion, capacity building including human resource development, early diagnosis and prompt treatment on integration with different levels of health care systems in a comprehensive manner. ${ }^{1,2}$ NPCDCS is currently focusing a major concentration towards building capacity of medical officers for service delivery and training of staff working for NCDs. It is expected that trained medical officers would be in a position not only to organize and supervise population based screening program but also to provide comprehensive treatment to those who are confirmed to have NCDs along with referral of cases that are in need of higher levels of care. This training would build capacity of Medical Officers to manage common uncomplicated NCDs at their level and also give best possible initial treatment in medical emergencies like myocardial infarction and stroke, before referring to higher level of care. Government's commitment to reduce premature mortality due to NCDs by one-third by 2030 as per sustainable development goals would not be possible unless the entire medical fraternity commits itself to this challenging goal. ${ }^{5}$ In this backdrop, the current study was conducted to (a) assess the Training need among medical officers regarding NPCDCS, (b) determine the efficacy of the training delivered towards them and (c) find out need for further training in future, if any.

\section{METHODS}

\section{Study type and study design}

Descriptive study with cross-sectional design.

\section{Study setting}

The State of West Bengal comprise 28 districts and health districts. ${ }^{6}$ The study was conducted among the medical officers including the block medical officers in six districts in the southern part of the State, namely, North 24-parganas, PurbaMedinipur, Nadia, Murshidabad, Rampurhat and Jhargram.

Study period: 3 months (May-July, 2018).

\section{Study population}

The medical officers and Block Medical Officers who were working at the same place of posting for the last 6 months were considered as study population.

\section{Sampling design}

Two-stage simple random sampling was followed. Despite the nationwide inception of NPCDCS was long back, it was rolled out in the state of West Bengal since 2016-17. ${ }^{6}$ Once the state-level training of trainers (TOT) was completed, it was decided for a strategic project implementation plan (PIP) for the $2^{\text {nd }}$ quarter of the year 2018 and the medical officers of districts of southern part of West Bengal were permitted to be trained at the district level. Hence, in the first stage, out of the total 18 districts covered in South Bengal, 6 (33\%) were selected following simple random sampling to allow representability. In the second stage, medical officers were selected from each of the districts who were posted over different CHCs and PHCs. The pay-roll was collected from district head quarter(s) with liaison with the district level health officials, and 40-45 M.Os were selected from each such district using simple random sampling. The participants for training were selected so that at least two medical officers could subsequently be deployed for running of the proposed NCD clinics, in each health care setting.

\section{Sample size}

In absence of any previous study on training need assessment regarding NPCDCS, prevalence level of training need for medical officers were considered as $50 \%$, to ensure maximum sample size. The complement of prevalence was also taken as $50 \%$. Assuming the precision level " $\mathrm{L} "=5 \%$ while $\mathrm{Z} \alpha=1.96$ at $95 \%$ C.I., using formula of $\left(\mathrm{Z}_{2} \mathrm{xPx}(1-\mathrm{P})\right) / \mathrm{L}_{2}$, the sample size was calculated as 385 . Considering finite population of medical officers as 1200 approximately in 6 selected districts, the required minimum sample size was 292 after finite population correction (FPC). Presuming 20\% nonresponse and midcourse dropout, final sample size was computed to be 351 . However, the study was conducted among 352 Medical Officers.

\section{Study tool}

The study was undertaken with an identical semistructured, pre-tested and validated 25 -item questionnaire (Cronbach's alpha >0.8) covering different levels of cognitive domain, with a maximum possible score of 100 marks. In this self-administered questionnaire, there was no provision for negative marking.

\section{Study technique and methods of data collection}

An one-day six-hours training was conducted among selected trainees in phased manner at each district head 
quarter. The training was delivered by the Principal Investigator (PI) who was an accredited trainer having participated in the Certified Training of Trainers (TOT) programme on $26^{\text {th }}$ and $27^{\text {th }}$ of April, 2018 at state head quarter. Pre and Post training assessment surveys were done on the same day to the training programme.

\section{Ethics}

Trainings were conducted on written orders from the State Health Directorate and informed consent was taken from each of the participants.

\section{RESULTS}

Age of the participants was $31 \pm 6.5$ years (mean \pm SD); $197(55.96 \%)$ were male and rest 155 (44.03\%) were female. Among 352 participants, 324 had MBBS qualification, among the rest, 19 had post graduate diploma and 9 were found to hold post graduate degree in any discipline. Average work experience of the M.O.s was 7.2 \pm 1.1 years. Mean \pm SD of post and pre-test scores were $77 \pm 23.5 \%$ and $34 \pm 12.9 \%$ respectively.
Dependent sample t-test showed significant difference between post and pre-test scores with $\mathrm{p}<0.000$ (Table 1). Negative correlation $(r=-0.474)$ between post-test and pretest scores were observed, which was statistically significant $(\mathrm{p}<0.000)$ indicating unmet training needs.

One way repeated measures Test was done using General Linear Model was done with time in the horizontal axis (over which pre-test and post-test scores were measured). "F" values were highly significant $(<0.001)$ as seen in Pillai's Trace, Wilk's Lambda etc. Partial Eta Squared values being 0.919 , implying that $91.9 \%$ of the variation between pre-test and post-test scores could be explained by "the training" (Table 2). Greenhouse-Geisser, HuynhFeldt and lower-bound reflected highly significant "F" values with $\mathrm{p}<0.000$; here Sphericity cannot be computed as only two levels were compared over time. Multivariate (repeated measures) tests, using Bonferroni pairwise comparisons also revealed highly significant " $F$ " values with $\mathrm{p}<0.000$.

Univariate (GLM) with pretest baseline score as Covariate was conducted and significant " $F$ " and partial eta square reflecting unmet training needs (Table 3 ).

Table 1: Distribution of scores by dependent sample t-test.

\begin{tabular}{|llllll|}
\hline Mean & SD & 95\% C.I. & & t & Sig.(2-tailed) \\
\hline $\mathbf{4 1 . 1 6 5}$ & 12.233 & Lower & Upper & 63.134 & 0.000 \\
\hline
\end{tabular}

Table 2: GLM-repeated measures analysis with time.

\begin{tabular}{|llll|}
\hline & F & Sig. & Partial eta squared \\
\hline Pilli's trace & 3985.87 & 0.000 & 0.919 \\
\hline Wilk's Lambda & & 0.90 \\
\hline
\end{tabular}

Table 3: Univariate (GLM) with Pretest baseline score as Covariate.

\begin{tabular}{|lllll|}
\hline & Mean square & F & Sig. & Partial eta squared \\
\hline Corrected model & 39247.68 & 1034.49 & 0.000 & 0.747 \\
\hline Intercept & 147424.54 & 3358.64 & 0.000 & 0.906 \\
\hline Pre-test & 39247.69 & 1034.9 & 0.000 & 0.747 \\
\hline
\end{tabular}

Table 4: Comparison between pretest scores, gain in score after training and residual gap even after receipt of training.

\begin{tabular}{|llll|}
\hline & Pre-test score $\%$ & Gain in score after training & $\begin{array}{l}\text { Residual gap between maximum } \\
\text { marks and post-test score }(\%)\end{array}$ \\
\hline Mean & 33.5000 & 41.1648 & 25.3352 \\
\hline N & 352 & 352 & 352 \\
\hline SD & 7.25914 & 12.23307 & 6.98726 \\
\hline
\end{tabular}

$\mathrm{P}$ value often depends on sample size, and even small differences in means result in statistically significant values, which may not carry any practical impact insofar as program management is concerned. Hence, Cohen's "d" is important; Cohen's " $\mathrm{d} "=\mathrm{t} / \sqrt{ }(\mathrm{N})=63.134 / \sqrt{ }(352)=$ 3.365. Thus as per accepted convention, the "effect size" of these series of training programs are highly effective ("Huge") as modified later on by Sawilowaky's addition.

The residual gap even after receipt of training was found to be $>25 \%$ which reiterates the needs of periodic retraining (Table 4). 


\section{DISCUSSION}

The age of the current study participants was in accordance to the study by Ainapure et al from Karnataka. ${ }^{7}$ In contrast to the current study, the above mentioned study was conducted among all the levels of stakeholders for NPCDCS programme implementation.? Regarding mean $\pm \mathrm{SD}$ of the pre and post-test scores, the current study had supporting evidence from the study by Framtz about risk factors of NCDs among common learners. ${ }^{8}$ Similar findings were also there in study by Choudhari et al from Gujarat. ${ }^{9}$ Similar to the current study, Liang et al also showed significant improvement as evident in post-training programme among students regarding life-effectiveness factors $(<0.001) .{ }^{10}$ Alessandri et al by Structural Equation Modelling Approach also showed effectiveness of intervention by significant improvement of post-test scores. ${ }^{11}$ Dauer et al had also similar findings regarding training intervention among nurses on radiation safety. ${ }^{12}$ Training efficacy as evident in the current study had also been emphasized by Muthén and Curran (1997). ${ }^{13}$ Similar findings were also there in studies by Dauar LT from New York City and also from a school-based study from Saudi Arabia. ${ }^{12}$ Somewhat in contrast to these, Caprara et al. emphasized effects of external variables as moderators. ${ }^{14}$ Knowledge gap, as evident in the current study had no comparative literature on extensive research.

\section{CONCLUSION}

Despite the fact that, none of the medical officers had work experience of not less than 5 years, but baseline working knowledge regarding NCD was dismal. After six hours of training, the improvement of on-site knowledge was significant as evidenced by scores. Residual knowledge gap needs to be addressed through periodic refresher training in future.

\section{Limitation of the study}

As the current study was conducted among six districts of West Bengal, extrapolation of findings might be erroneous for the other districts. As the post-training test was conducted within very short time gap, assessment might be based on rote memory. A future study with a minimum time gap of 1 month may be better to assess actual knowledge gain.

\section{ACKNOWLEDGEMENTS}

The authors express their gratitude towards Dr. Ajoy Chakrabarty, Director of Health Services, West Bengal, India for his support and guidance.

\footnotetext{
Funding: West Bengal State Health and Family Welfare Samity, WB, India

Conflict of interest: None declared

Ethical approval: The study was approved by the Institutional Ethics Committee
}

\section{REFERENCES}

1. Park K. Park's Textbook of Preventive And Social Medicine. 24th edition. Jabalpur (M.P.), India: M/S Banarasidas Bhanot; 2017; 380-493.

2. Training Module for Medical Officers for National Programme for Prevention and Control of Cancer, Diabetes, Cardiovascular Diseases and Stroke (NPCDCS). National Centre for Disease Control. Directorate General of Health Services. MoHFW, GOI. 2010.

3. Ministry of Health and Family Welfare. National Health System Resource Centre. National Rural Health Mission in eleventh five year plan (20072012) strengthening public health systems. Government of India. 2012;7:1.

4. Planning Commission (GOI). 12th five year plan. New Delhi; 2012-2017.

5. Sustainable Development Solution Network: A Global Initiative for U.N. Indicators and monitoring framework for the SDGs. Revised working draft, March 20, 2015.

6. Health on the March 2013-2014. West Bengal State Bureau of Health Intelligence. Directorate of Health Sciences, Government of West Bengal. Available at www.wbhealth.gov.in. Accessed on 3 January 2019.

7. Ainapure K, Sumit K, Pattanshetty SM. A study on implementation of national programme for prevention and control of cancer, diabetes, cardiovascular diseases and stroke in Udupi district, Karnataka. Int J Community Med Public Health. 2018;5(6):2384-7.

8. Framtz JM. A knowledge assessment questionnaire relating to risk factors for chronic disease of lifestyle for high school learners: validity and reliability. JCHS. 2008;3(1).

9. Choudhari A, Rami K, Thakor N. Assessment of knowledge regarding non-communicable diseases and their risk factors among students of higher secondary school: an interventional study. Int J Med Sci Public Health. 2016;5(1):115-8

10. Liang G, Bo N. The pretest-posttest design and measurement of outward-bound-type program effects on personal development. Procedia Earth Planetary Sci. 2009;1:1717-22.

11. Allesandri G, Zuffianò A, Perinelli E. Evaluating Intervention Programs with a Pretest-Posttest Design: A Structural Equation Modeling Approach. Front Psychol. 2017.

12. Dauer LT, Kelvin JF, Horan CL, Germain JS. Evaluating the effectiveness of a radiation safety training intervention for oncology nurses: a pretestintervention-posttest study. BMC Medical Education 2006;6:32.

13. Muthén BO, Curran PJ. General longitudinal modeling of individual differences in experimental designs: a latent variable framework for analysis and power estimation. Psychol. Methods. 1997;2:371-402. 
14. Caprara GV, Luengo K, Gerbino M, Zuffianò A, Alessandri, G, Vecchio, G, et al. Positive effects of promoting prosocial behavior in early adolescents: evidence from a school-based intervention. Int $\mathrm{J}$ Behav Dev. 2014;4:386-96.
Cite this article as: Saha I, Mitra S, Chatterjee A, Mukhopadhyay J, Chatterjee C. Assessment of training need and training efficacy for national program for prevention and control of cancer, diabetes, cardiovascular diseases and stroke among medical officers of West Bengal, India. Int J

Community Med Public Health 2019;6:3056-60. 